\title{
Effects of Low-Dose Dopamine Infusion on Cardiovascular and Renal Functions, Cerebral Blood Flow, and Plasma Catecholamine Levels in Sick Preterm Neonates
}

\author{
ISTVAN SERI, GABOR RUDAS, ZSUZSA BORS, BELA KANYICSKA, AND TIVADAR TULASSAY \\ Joint Program in Neonatology, Children's Hospital and Harvard Medical School, Boston, Massachusetts 02115 \\ [I.S.]; First [T.T.] and Second [G.R., Z.B.] Departments of Pediatrics, Semmelweis Medical School; and Institute \\ of Experimental Medicine [B.K.J, Academy of Sciences, Budapest, Hungary
}

\begin{abstract}
Effects of 2 and $4 \mu \mathrm{g} / \mathrm{kg} / \mathrm{min}$ dopamine infusion on cardiovascular and renal functions, cerebral blood flow (CBF) and plasma catecholamine levels were studied in sick preterm neonates during the first four days of life. Preterm infants were found to have an enhanced responsiveness to the pressor effects of dopamine during this period. Comparison of the renal effects of 2 and $4 \mu \mathrm{g} / \mathrm{kg} /$ min dopamine in 61 preterm infants indicate that $2 \mu \mathrm{g} / \mathrm{kg} /$ min dopamine induces maximum diuresis and natriuresis during the first day of life provided that systemic blood pressure is within the predicted normal range. Although administration of $4 \mu \mathrm{g} / \mathrm{kg} / \mathrm{min}$ dopamine induces further increases in blood pressure and glomerular filtration rate, urine output and sodium excretion remain similar to that on $2 \mu \mathrm{g} / \mathrm{kg} / \mathrm{min}$ of the drug. These findings demonstrate that the direct tubular effects of dopamine play an important role in the diuretic and natriuretic action of the drug in the one-day old preterm infant. In five preterm neonates, changes in CBF transiently paralleled the dopamine-induced alterations in systemic blood pressure indicating that autoregulation of CBF is impaired but not completely ineffective in the one-day old preterm infant. In eight term neonates, increases in blood pressure had no effect on CBF. Measurements of plasma dopamine and norepinephrine levels in 14 preterm neonates and five children suggest that decreased metabolism of dopamine may contribute to the enhanced pressor responsiveness to dopamine in sick preterm infants. Based on these findings, we propose that dopamine should be started at $2 \mu \mathrm{g} / \mathrm{kg} / \mathrm{min}$ in the hypotensive and/or oliguric preterm infant, and that the dose should be increased in a step-wise manner tailored to the cardiovascular and renal response to the patient. (Pediatr Res 34: 742-749, 1993)
\end{abstract}

\section{Abbreviations}

ACA, anterior cerebral artery ANOVA, analysis of variance CBF, cerebral blood flow

$C_{c r}$, creatinine clearance

DA, dopamine (study group)

DBP, diastolic blood pressure EDFV, end-diastolic flow velocity

ESFV, end-systolic flow velocity

GFR, glomerular filtration rate

Received February 17, 1993; accepted August 6, 1993.

Correspondence and reprint requests: Istvan Seri, M.D., Ph.D., Joint Program in Neonatology, Brigham and Women's Hospital, Harvard Medical School, 75 Francis St., Boston, MA 02115.
Hct, hematocrit

IVH, intraventricular hemorrhage

PI, pulsatility index

SBP, systolic blood pressure

$\mathrm{U}_{\mathrm{NH} 4}$, urinary ammonium excretion

$U_{T A}$, titratable acidity

$U_{v}$, urine output

$U_{U N}$, urea nitrogen excretion

Dopamine has been the drug of choice to combat hypotension, impaired tissue perfusion and oliguria in critically ill neonates (1-5). Based mostly on extrapolation of data from findings in older infants and children, earlier studies have suggested that the minimally effective dose of dopamine in the sick term neonate is 10 to $15 \mu \mathrm{g} / \mathrm{kg} / \mathrm{min}(6,7)$. Furthermore, despite the differences between preterm and term infants in the maturation of their cardiovascular, renal, and endocrine systems, the minimally effective dose of dopamine for the preterm neonate has been assumed to be similar to that of the term infant (1). However, several recent reports indicate that lower doses of the drug may be effective in both term and preterm neonates (3-5). In addition, we have also suggested that the minimally effective cardiovascular dose of dopamine may be even lower in preterm than in term infants $(3,8,9)$. However, this enhanced cardiovascular responsiveness of the preterm infant to dopamine has not been confirmed.

The role of the drug-induced cardiovascular and renal hemodynamic changes in the renal effects of dopamine has been widely recognized in adults $(10,11)$ as well as in newborn infants $(1,2$, 6). Recent findings also demonstrate the importance of the direct tubular actions of dopamine in producing diuresis and natriuresis $(9,12-16)$. However, it is not known whether immaturity of renal function in the preterm neonate affects the contribution of the direct tubular actions of dopamine to the drug-induced diuresis and natriuresis.

The pathogenesis of IVH and periventricular leukomalacia is almost certainly related to changes in cerebral hemodynamics (17-19). Because autoregulation of CBF in preterm neonates is impaired $(20,21)$, enhanced responsiveness of these infants to the pressor effects of dopamine may put them at risk for the development of IVH and/or periventricular leukomalacia. However, the effect of the dopamine-induced hemodynamic changes on CBF in the sick preterm infant has not been clarified. Furthermore, it is not known whether this effect changes with development.

The present study examines the effects of dopamine on cardi- 
ovascular and renal functions, $\mathrm{CBF}$, and plasma catecholamine levels in sick preterm infants during the first days of life. We compared cardiovascular and renal functions in preterm infants with and without low-dose dopamine treatment. We also examined the changes in CBF during low-dose dopamine infusion in preterm infants and compared the findings with those in term neonates. If responsiveness to the hemodynamic actions of dopamine is enhanced in preterm infants, several mechanisms could account for this phenomenon. These mechanisms include maturation-dependent differences in the order of adrenergic receptor sensitivity (22), the unique hormonal milieu of preterm infants $(1,9,23)$, and immature metabolic function. We therefore also measured plasma dopamine clearance rates as a possible contributing mechanism to the proposed enhanced cardiovascular responsiveness to dopamine in the preterm infant.

\section{PATIENTS AND METHODS}

We examined the effects of two doses of dopamine (2 versus $4 \mu \mathrm{g} / \mathrm{kg} / \mathrm{min}$ ) on systemic blood pressure, renal function, CBF, and plasma catecholamine levels in sick preterm neonates. Studies on cardiovascular and renal function and CBF were performed on the first day of life, whereas plasma catecholamine levels were measured during the first $4 \mathrm{~d}$ of life. In the studies on cardiovascular and renal function, normotensive preterm infants served as controls, and oliguric and mildly or moderately hypotensive preterm neonates requiring 2 or $4 \mu \mathrm{g} / \mathrm{kg} / \mathrm{min}$ dopamine formed the two study groups (DA-2 and DA-4 groups, respectively). In the studies on $\mathrm{CBF}$, hypotensive preterm and term neonates were studied and cardiovascular and CBF measurements were performed on both 2 and $4 \mu \mathrm{g} / \mathrm{kg} / \mathrm{min}$ of dopamine. Thus, these patients also served as their own controls. In the studies on plasma catecholamine levels, normotensive children receiving $2 \mu \mathrm{g} / \mathrm{kg} / \mathrm{min}$ dopamine served as controls and hypotensive preterm neonates formed the study group. In the preterm infants, measurements of plasma dopamine and norepinephrine levels were performed on both 2 and $4 \mu \mathrm{g} / \mathrm{kg} / \mathrm{min}$ dopamine.

Patients enrolled in the studies were cared for at the neonatal intensive care units of the 1st Department of Obstetrics/Gynecology and the 2nd Department of Pediatrics, Semmelweis Medical School, Budapest, Hungary, and at the Division of Nephrology, 1st Department of Pediatrics, Semmelweis Medical School. All the infants required ventilatory support in the form of nasal/ nasopharyngeal continuous positive airway pressure or intermittent mandatory ventilation and received nothing by mouth at the time of the studies. Heart rate was monitored continuously by conventional techniques. Blood pressure was measured either with oscillometry or from an umbilical artery catheter connected to a pressure transducer. Each data point of systolic and diastolic blood pressures is the average of two to three individual measurements. Routine supportive intensive care and monitoring of the patients were performed according to conventional guidelines and clinical practice. In most of the patients, dopamine (Dopamin, Nattermann, Cologne, Germany) was infused into a peripheral vein by calibrated infusion pumps. In some neonates, dopamine was administered centrally into the aorta or the inferior vena cava through indwelling catheters. The five children ( 5 to $15 \mathrm{y}$ of age) participating in the studies had mild renal diseases with normal renal functions.

The special techniques and analytical methods used in the different segments of this study are described in detail below. Informed parental consent was obtained in all cases and the studies were approved by the institutional scientific committees.

Cardiovascular and renal function studies. These studies were performed on the first day of life in 61 preterm infants. Patients were divided into three groups. Clinical data and baseline SBP, DBP, and $U_{V}$ are shown in Table 1 . Infants in the control group $(n=21)$ did not receive dopamine therapy during the study, whereas patients in the DA-2 group $(n=31)$ received dopamine infused at a rate of $2 \mu \mathrm{g} / \mathrm{kg} / \mathrm{min}$. Renal function studies in these two groups were published earlier (24). Infants who required dopamine at a dose of $4 \mu \mathrm{g} / \mathrm{kg} / \mathrm{min}$ to maintain appropriate systemic blood pressures were assigned to the DA-4 group $(n=$ $10)$. The groups did not differ significantly in birth weight ( $p=$ 0.072 , ANOVA), gestational age ( $p=0.301$, ANOVA), or underlying diseases (Table 1). Cardiovascular and renal function data of the control group and the findings obtained in the DA-2 and DA-4 groups during dopamine treatment are compared in this segment of the study reflecting an unpaired study design.

Infants in the control group manifested clinical signs of poor peripheral perfusion but had no systemic hypotension or significant oliguria $\left(\mathrm{U}_{\mathrm{v}}=0.033 \pm 0.012 \mathrm{~mL} / \mathrm{min} / \mathrm{kg}\right)$. These patients received $1 \mathrm{~g} / \mathrm{kg}$ human albumin. Urine was collected for an 8 to $12-\mathrm{h}$ period. Patients in the DA-2 group had oliguria and mild systemic hypotension for at least $1 \mathrm{~h}$ before enrollment (Table 1). These preterm infants received $1 \mathrm{~g} / \mathrm{kg}$ human albumin followed by a dopamine infusion at a dose of $2 \mu \mathrm{g} / \mathrm{kg} / \mathrm{min}$. An 8to 12-h urine collection was started when blood pressure stabilized on dopamine therapy ( 30 to $60 \mathrm{~min}$ after initiation of dopamine treatment). Patients in the DA-4 group presented with oliguria and systemic hypotension (Table 1). Infusion of $1-2 \mathrm{~g} /$ $\mathrm{kg}$ human albumin resulted only in a transient increase in blood pressure. Therefore, a dopamine infusion of $2 \mu \mathrm{g} / \mathrm{kg} / \mathrm{min}$ was started and the dose was shortly increased to $4 \mu \mathrm{g} / \mathrm{kg} / \mathrm{min}$ to achieve blood pressures in the predicted normal range. At that time, an 8- to 12-h urine collection was initiated. Total crystalloid $(60-80 \mathrm{~mL} / \mathrm{kg} / \mathrm{d})$ administration was not different among the groups during the first day of life. However, patients in the DA4 group tended to receive more colloid than the infants in the two other groups ( 2 versus $1 \mathrm{~g} / \mathrm{kg}$ albumin).

At the midpoint of the 8- to 12-h urine collections, blood samples were taken for plasma electrolyte, creatinine, and osmolality analysis. Urinary and plasma sodium, potassium, phosphorus, and creatinine were measured by standard laboratory techniques. $U_{T A}$ and $U_{\mathrm{NH}_{4}}$ were determined from urine samples taken under anaerobic conditions using ion-selective electrodes (24). Urea nitrogen and osmolality were measured by spectrophotometry and freezing point depression, respectively. Fractional excretion of sodium and free water clearance were calculated as described earlier (24).

$C B F$ studies. CBF was measured in a separate group of five preterm infants and eight term neonates. Clinical data and baseline SBP and DBP are shown in Table 2. Patients were enrolled who met the following criteria: $I$ ) $<24 \mathrm{~h}$ of age; 2) hypotension [SBP >15 $\mathrm{mm} \mathrm{Hg}$ below the predicted normal value for gestational and postnatal age $(25,26)]$; 3) $\mathrm{O}_{2}$ requirement to maintain adequate arterial $\mathrm{PO}_{2}$ with or without the need for mechanical ventilation; and 4) no significant change in $\mathrm{pH}$, $\mathrm{PCO}_{2}, \mathrm{PO}_{2}$, heart rate, and $\mathrm{Hct}$ during the study.

Changes in ESFV and EDFV in the ACA as well as the calculated PI $[\mathrm{PI}=\mathrm{ESFV}-\operatorname{EDFV} / \operatorname{ESFV}(\%)(27,28)]$ were used to assess changes in CBF during the study. ESFV and EDFV were measured by real-time duplex Doppler ultrasound and $M$ mode echocardiography (model: Picker LSC 7000, Picker, Inc., Canton, MA). Scans were performed with $5-\mathrm{MHz}$ transducers for real-time imaging and the Doppler studies. The ACA was insonated through the anterior fontanel at its curve around the corpus callosum, where the angle of insonation is $\sim 0^{\circ}$. Reliable blood flow velocity wave forms of the ACA with maximal amplitudes were obtained by optimizing the sample volume position using acoustic and visual control. Arterial blood gases and Hct values were obtained from indwelling arterial catheters. Heart rate, blood pressure, and $\mathrm{PO}_{2}$ were monitored as part of routine clinical care. Blood pressure measurements were performed via oscillometry.

After baseline Doppler ultrasound measurements of CBF velocity and heart rate, blood pressure, and arterial blood gas determinations (control data), dopamine infusion was begun at $2 \mu \mathrm{g} / \mathrm{kg} / \mathrm{min}$. Doppler ultrasound measurements and heart rate, blood pressure, and arterial blood gas determinations were re- 
Table 1. Clinical data of patients enrolled in studies on cardiovascular and renal functions*

\begin{tabular}{lccc}
\hline & Control group & DA-2 group & DA-4 group \\
\hline$n$ & 20 & 31 & 10 \\
Birth weight (g) & $1949 \pm 467$ & $1900 \pm 372$ & $1815 \pm 476$ \\
GA (wk) & $33.7 \pm 2.3$ & $32.8 \pm 1.6$ & $33.1 \pm 2.5$ \\
Diagnosis & & & 4 \\
$\quad$ HMD & 12 & 19 & 5 \\
Sepsis/pneumonia & 8 & 22 & 1 \\
$\quad$ Hydrops & & & $29.3 \pm 5.5 \dagger$ \\
Baseline SBP (mm Hg) & $46.1 \pm 4$ & $41.7 \pm 7.2$ & $14.8 \pm 6.9 \dagger$ \\
Baseline DBP (mm Hg) & $25.1 \pm 2$ & $22.0 \pm 6.8$ & $0.012 \pm 0.005 \ddagger \S$ \\
Baseline Uv $(\mathrm{mL} / \mathrm{kg} / \mathrm{min})$ & $0.033 \pm 0.012$ & $0.014 \pm 0.004 \ddagger \S$ & \\
\hline
\end{tabular}

* GA, gestational age; HMD, hyaline membrane disease.

$\dagger p<0.05 v s$ control and DA-2 groups (ANOVA).

$\ddagger p<0.05$ vs control (ANOVA).

$\S$ Secondary to the low baseline $U_{v}$, the changes in clinical condition, and thus the early need for treatment in the DA-2 and DA-4 groups, baseline $U_{v}$ could not be accurately determined in all the patients.

Table 2. Clinical data of patients enrolled in studies on $C B F$ measurements*

\begin{tabular}{lcc}
\hline & Preterm infants & Term infants \\
\hline$n$ & 5 & 8 \\
Birth weight (g) & $1482 \pm 476$ & $3194 \pm 456$ \\
GA (wk) & $30.4 \pm 2.9$ & $38.9 \pm 1.1$ \\
Diagnosis & & \\
$\quad$ HMD & 3 & \\
Sepsis/pneumonia & 2 & 1 \\
TTN/presumed sepsis & & 5 \\
MAS & & 1 \\
Baseline SBP (mm Hg) & $32.8 \pm 4.8$ & $46.4 \pm 4.8$ \\
Baseline DBP (mm Hg) & $12.6 \pm 2.4$ & $27.8 \pm 5.1$ \\
\hline
\end{tabular}

* GA, gestational age; HMD, hyaline membrane disease; TTN, transient tachypnea of the newborn; MAS, meconium aspiration syndrome.

peated at $\sim 20 \mathrm{~min}$ (range: 15 to $30 \mathrm{~min}, \mathrm{DA} 2 / 20$ data) and $\sim 60$ min (range: 50 to $90 \mathrm{~min}, \mathrm{DA}-2 / 60$ data) during the infusion of $2 \mu \mathrm{g} / \mathrm{kg} / \mathrm{min}$ of dopamine. The dose of dopamine was then doubled, and all measurements were repeated at $\sim 20 \mathrm{~min}$ (range: 15 to $30 \mathrm{~min}$ ) and $\sim 60 \mathrm{~min}$ (range: 50 to $90 \mathrm{~min}$ ) (DA-4/20 and DA-4/60 data, respectively). In two infants, the dose of dopamine had to be increased to $8 \mu \mathrm{g} / \mathrm{kg} / \mathrm{min}$ to achieve blood pressures in the desired range. Hct was measured initially and repeated with the last blood gas determination in each patient.

Plasma dopamine and norepinephrine measurements. These studies were performed in a separate group of 14 preterm neonates requiring continuous positive airway pressure or intermittent mandatory ventilation and 2 and $/$ or $4 \mu \mathrm{g} / \mathrm{kg} / \mathrm{min}$ dopamine therapy for systemic hypotension and mildly decreased $U_{V}\left(U_{V}\right.$ $=0.027 \pm 0.012 \mathrm{~mL} / \mathrm{min} / \mathrm{kg}$ ) during the first $4 \mathrm{~d}$ of life. Plasma dopamine clearance rate $(\mathrm{L} / \mathrm{kg} / \mathrm{min})$ was calculated as infusion rate $(\mu \mathrm{mol} / \mathrm{L} / \mathrm{kg} / \mathrm{min}) /[$ steady state dopamine concentration $(\mu \mathrm{mol} / \mathrm{L})-$ baseline dopamine concentration $(\mu \mathrm{mol} / \mathrm{L})]$ assuming no change in endogenous dopamine secretion. Changes in blood pressure were followed by oscillometry. Four- to 6-h urine collections were obtained during the control period and during dopamine therapy after blood pressures had normalized. To obtain control measurements, plasma dopamine and norepinephrine levels were also determined and plasma dopamine clearance rate was calculated in five children presenting with mild renal diseases and normal renal functions. Clinical data of the preterm infants and children enrolled in this segment of the study are summarized in Table 3.

In 14 infants, 20 baseline samples for plasma dopamine and norepinephrine measurements were drawn to determine whether significant spontaneous fluctuations in baseline catecholamine
Table 3. Clinical data of patients enrolled in studies on plasma catecholamine level measurements*

\begin{tabular}{lcc}
\hline & Preterm infants & Children \\
\hline$n$ & 14 & 5 \\
Birth weight (g) & $1543 \pm 307$ & \\
GA (wk) & $30.7 \pm 1.8$ & \\
PA (d/y) & $2.1 \pm 1.7$ & $9.2 \pm 3.7$ \\
Diagnosis & 7 & \\
$\quad$ HMD & 7 & \\
$\quad$ Sepsis/pneumonia & & 5 \\
$\quad$ Mild renal disease & & 5 \\
\hline
\end{tabular}

* GA, gestational age; PA, postnatal age; HMD, hyaline membrane disease.

levels occurred (control data). Dopamine was then started at 2 $\mu \mathrm{g} / \mathrm{kg} / \mathrm{min}$. At this dose, 20 and 23 samples were analyzed for plasma dopamine and norepinephrine determinations, respectively (DA-2 data). In 11 preterm neonates, the dose of dopamine was then increased to $4 \mu \mathrm{g} / \mathrm{kg} / \mathrm{min}$ to achieve the desired increase in systemic blood pressure (see Results). At this dose, 13 and 19 samples were analyzed for plasma dopamine and norepinephrine determinations, respectively (DA-4 data). In six patients, DA-2 and DA-4 norepinephrine levels were determined without corresponding dopamine level measurements.

In the five children, 11 baseline samples for plasma dopamine and norepinephrine determinations were drawn (control data). Dopamine was then started at $2 \mu \mathrm{g} / \mathrm{kg} / \mathrm{min}$ and 19 samples were analyzed for plasma dopamine and norepinephrine levels (DA2 data). Blood samples were taken through a peripheral cannula placed before the study to avoid possible stress-induced changes in plasma catecholamine levels.

A maximum of seven samples, for a total of $4.2 \mathrm{~mL}$ of blood, were removed from each patient. In the preterm infants, it was replaced incrementally with cross-matched packed red blood cells. The samples were immediately transferred to specially prepared ice-cold test tubes, mixed, and centrifuged at $4^{\circ} \mathrm{C}$, and the plasma was separated and kept frozen at $-70^{\circ} \mathrm{C}$ until analysis. Plasma dopamine and norepinephrine levels were determined by radioenzymatic assay (29). The sensitivity of the assay was $1.96-2.61$ and $0.15-0.3 \mathrm{nmol} / \mathrm{L}$ for dopamine and norepinephrine, respectively. Intraassay and interassay coefficients of variation were $<5 \%$ and $<10 \%$, respectively.

Statistical analysis. Data collected are given as means \pm SD unless indicated otherwise. Paired and unpaired $t$ test, simple regression analysis, and one-factor ANOVA (Scheffe $F$ test or Fischer's protected least squares difference test) were used for statistical analysis of the data where applicable. $p<0.05$ was considered significant. 


\section{RESULTS}

Effect of 2 and $4 \mu \mathrm{g} / \mathrm{kg} / \mathrm{min}$ dopamine on cardiovascular and renal function. SBP and DBP in untreated preterm infants (control group) and in infants treated with 2 and $4 \mu \mathrm{g} / \mathrm{kg} / \mathrm{min}$ dopamine infusion (DA-2 and DA-4 groups, respectively) are shown in Table 4. Baseline SBP and DBP were significantly lower in the DA-4 group ( $p<0.05$ versus control and DA-2 groups). Dopamine administration resulted in significant increases in SBP and DBP in both the DA-2 and DA-4 group ( $p$ $<0.05$ versus pretreatment values within the groups). A comparison of blood pressures of the DA-2 and DA-4 groups during dopamine treatment and blood pressures in the control group revealed significantly higher values only in the DA-4 group (Table 4 and Fig. 1, $p<0.05$ versus the control and DA-2 groups). No significant difference was seen in heart rate among the groups before and during dopamine treatment. Furthermore, heart rate did not change significantly within the groups during the study.

Findings on renal function in the three groups are summarized in Figure 1. During dopamine infusion, $U_{v}$, urinary sodium excretion, fractional excretion of sodium, urinary phosphorus excretion, and $U_{T A}$ were not different in the DA-2 and DA-4 groups and were significantly higher than those in the untreated control group $(p<0.05)$. $\mathrm{C}_{\mathrm{cr}}$, a somewhat limited but accepted clinical measure of GFR in the neonate (23), only increased significantly when the rise in blood pressure also became significant with $4 \mu \mathrm{g} / \mathrm{kg} / \mathrm{min}$ dopamine (DA-4 group). Free water clearance significantly decreased during dopamine treatment irrespective of the dose, whereas $U_{U N}$ decreased significantly only in the DA-2 group. Urinary potassium excretion and $U_{\mathrm{NH} 4}$ excretion did not differ significantly among the groups. When compared with the pretreatment values (Table 1), $U_{V}$ increased significantly during dopamine infusion in both the DA-2 and the DA-4 groups $(p<0.05)$.

Effect of 2 and $4 \mu \mathrm{g} / \mathrm{kg} / \mathrm{min}$ dopamine on $C B F$. In both the term and the preterm infants, mean values of heart rate, $\mathrm{pH}$, $\mathrm{PCO}_{2}, \mathrm{PO}_{2}$, transcutaneous $\mathrm{O}_{2}$, and $\mathrm{Hct}$ were within the normal range at the start of the study and no significant changes occurred during the experimental period. Blood pressures and PI before and during 2 and $4 \mu \mathrm{g} / \mathrm{kg} / \mathrm{min}$ dopamine infusion in preterm and term neonates are shown in Figure 2.

In the moderately hypotensive term neonates, the PI was in the normal range ( $\sim 65$ to $75 \%$ ) during the control period (Fig. 2 , upper panel). Administration of $2 \mu \mathrm{g} / \mathrm{kg} / \mathrm{min}$ dopamine did not induce significant changes in blood pressure or PI at either $\sim 20$ or $\sim 60 \mathrm{~min}$ after the initiation of drug infusion (DA-2/20 and DA-2/60 periods, respectively). In contrast, $4 \mu \mathrm{g} / \mathrm{kg} / \mathrm{min}$ dopamine significantly increased SBP and DBP in both the DA$4 / 20$ and DA-4/60 periods $(p<0.05)$. However, despite the significant rise in blood pressure, the PI remained unchanged in

Table 4. SBP and DBP $(\mathrm{mm} \mathrm{Hg})$ in preterm neonates requiring no dopamine therapy (control group) and in preterm infants treated with 2 and $4 \mu \mathrm{g} / \mathrm{kg} / \mathrm{min}$ dopamine (DA-2 and $D A-4$ group, respectively) before (baseline) and during drug infusion (DA)

\begin{tabular}{lccc}
\hline & $\begin{array}{c}\text { Control } \\
\text { group } \\
(n=20)\end{array}$ & $\begin{array}{c}\text { DA-2 } \\
\text { group } \\
(n=31)\end{array}$ & $\begin{array}{c}\text { DA-4 } \\
\text { group } \\
(n=10)\end{array}$ \\
\hline Baseline SBP & $46.1 \pm 4$ & $41.7 \pm 7.2$ & $29.3 \pm 5.5^{*}$ \\
SBP during DA & & $47.9 \pm 6 \dagger$ & $56.4 \pm 6.6 \dagger \ddagger$ \\
Baseline DBP & $25.1 \pm 2$ & $22 \pm 6.8$ & $14.8 \pm 4.6^{*}$ \\
DBP during DA & & $27.4 \pm 4 \dagger$ & $32.3 \pm 6.9 \dagger \ddagger$ \\
\hline
\end{tabular}

$* p<0.05$ vs baseline SBP/DBP in control and DA-2 groups (ANOVA).

$\dagger p<0.05 v s$ baseline in the same group (paired $t$ test).

$\ddagger p<0.05 v s$ baseline SBP/DBP in control group and during DA SBP/DBP in DA-2 group (ANOVA).
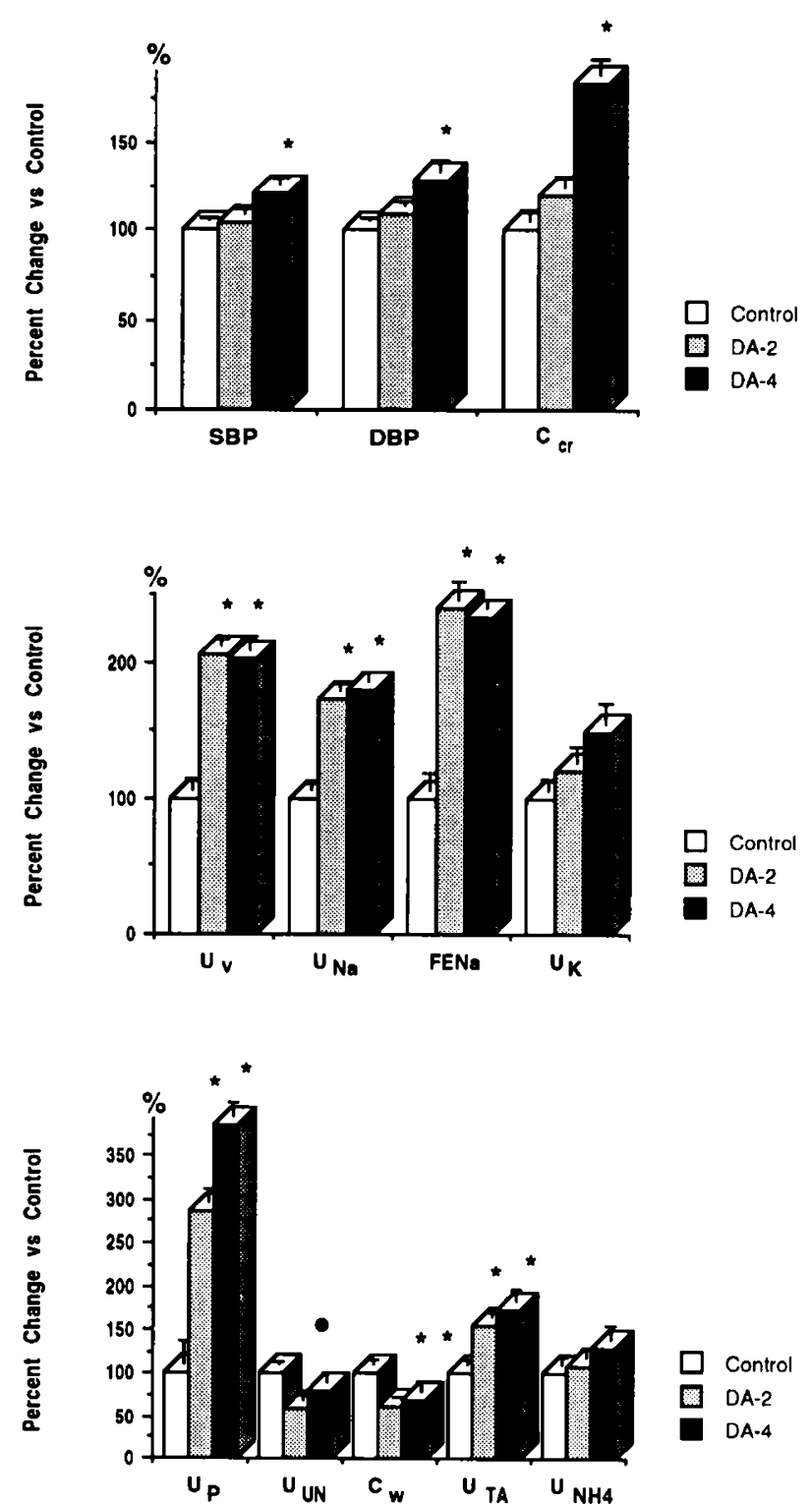

Fig. 1. SBP, DBP, and $C_{\mathrm{cr}}$ (upper panel); $\mathrm{U}_{\mathrm{v}}$, sodium excretion $\left(U_{\mathrm{Na}}\right)$, fractional excretion of sodium ( FENa), and potassium excretion $\left(U_{K}\right)$ (middle panel); and phosphorus excretion $\left(U_{P}\right), \mathrm{U}_{\mathrm{UN}}$, free water clearance $\left(C_{W}\right), \mathrm{U}_{\mathrm{TA}}$, and $\mathrm{U}_{\mathrm{NH} 4}$, (lower panel) shown as percent change (mean \pm SEM) vs untreated controls (control group) in preterm infants during the infusion of 2 and $4 \mu \mathrm{g} / \mathrm{kg} / \mathrm{min}$ dopamine (DA- 2 group and DA-4 group, respectively). ${ }^{*}, p<0.05$ vs control group; $\bullet, p<0.05$ vs control group and DA-4 group; ANOVA.

the three term infants in whom complete sets of measurements were obtained. ESFV and EDFV also did not change during the study.

In the hypotensive preterm neonates, the PI was also in the normal range ( $\sim 65$ to $75 \%)$ during the control period (Fig. 2, lower panel). Infusion of $2 \mu \mathrm{g} / \mathrm{kg} / \mathrm{min}$ dopamine tended to increase the SBP and DBP. However, only the increase in SBP at DA-2/60 reached statistical significance $(p<0.05$ versus control). Despite the only borderline rise in the blood pressure, PI significantly decreased at DA-2/20 $(p<0.05$ versus control, DA-2/60 and DA-4/60), whereas ESFV and EDFV increased in each patient with a trend of a somewhat more pronounced elevation in ESFV (not shown). Because the changes in ESFV and EDFV account for the change in PI, CBF was elevated during this period $(27,28)$. Although the elevation in blood pressure was sustained on $2 \mu \mathrm{g} / \mathrm{kg} / \mathrm{min}$ dopamine infusion, the 

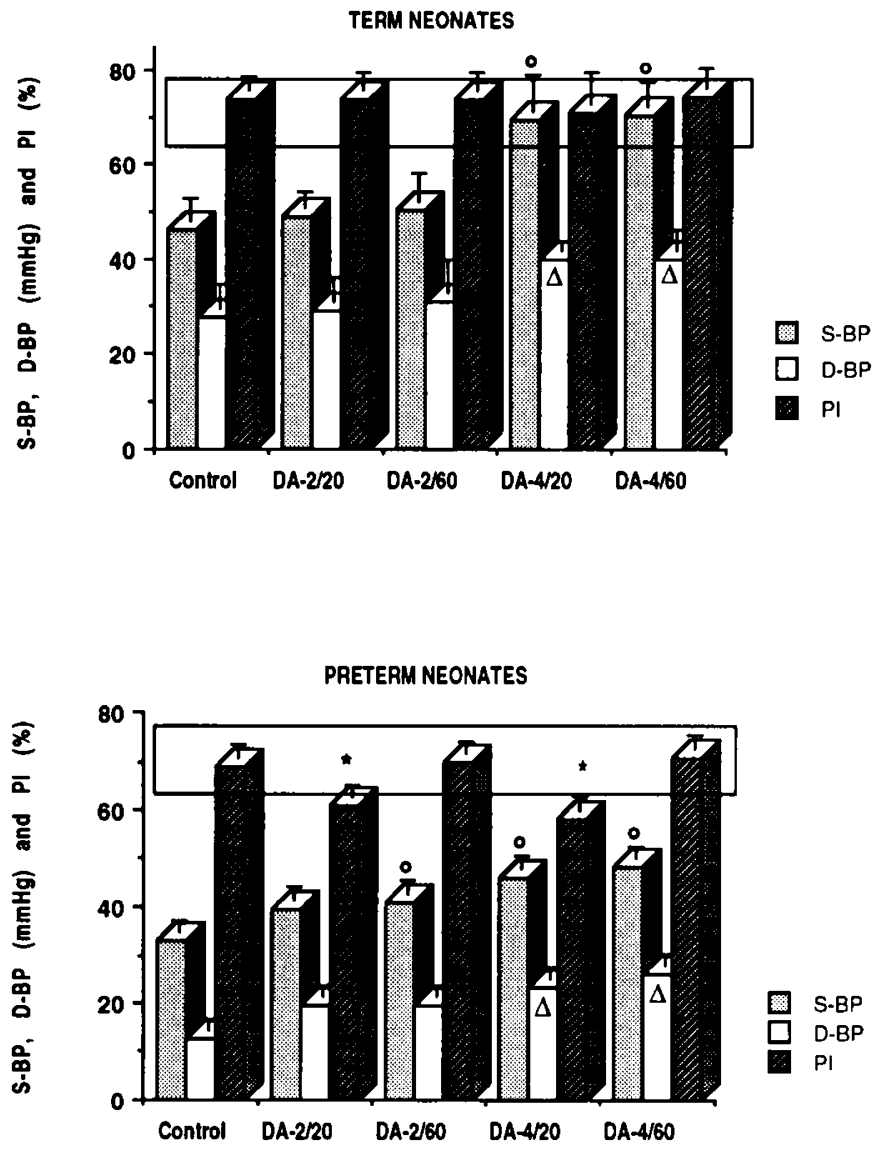

Fig. 2. Systolic (S-BP) and diastolic (D-BP) blood pressure $(\mathrm{mm} \mathrm{Hg})$, and PI (\%) in eight term (upper panel) and five preterm (lower panel) infants before (control) and during 2 (DA-2) and 4 (DA-4) $\mu \mathrm{g} / \mathrm{kg} / \mathrm{min}$ dopamine therapy. Measurements were performed at $\sim 20$ and $\sim 60 \mathrm{~min}$ on DA-2 (DA-2/20 and DA-2/60, respectively) as well as on DA-4 (DA$4 / 20$ and $D A-4 / 60$, respectively). The box represents normal range for PI. O, $p<0.05$ vs control (preterm neonates) and control, DA-2/20, and DA-2/60 (term neonates) S-BP (ANOVA); $\Delta, p<0.05 v s$ control D-BP (ANOVA); ${ }^{*}, p<0.05 v s$ control, DA-2/60, and DA-4/60 PI (ANOVA).

PI, ESFV, and EDFV returned to control levels by 50 to $90 \mathrm{~min}$ after the initiation of drug infusion (at DA-2/60).

To achieve and maintain blood pressures in the predicted normal range $(25,26)$, the dose of dopamine was increased to 4 $\mu \mathrm{g} / \mathrm{kg} / \mathrm{min}$ in three of the preterm infants and to $8 \mu \mathrm{g} / \mathrm{kg} / \mathrm{min}$ in the remaining two preterm neonates. Both SBP and DBP increased significantly. At $\sim 20 \mathrm{~min}$ after the initiation of the higher doses (DA-4/20), PI again significantly decreased $(p<$ 0.05 versus DA-2/60 and DA-4/60) and ESFV and EDFV increased (not shown), indicating a concomitant increase in CBF. Despite the sustained significant elevation in the blood pressure, however, PI, ESFV, and EDFV again returned to normal at DA$4 / 60$.

Effect of 2 and $4 \mu \mathrm{g} / \mathrm{kg} / \mathrm{min}$ dopamine on plasma catecholamine levels. In this group of preterm infants, SBP increased significantly from $37.1 \pm 4.6 \mathrm{~mm} \mathrm{Hg}$ to $44.8 \pm 5.1$ and $54.9 \pm$ $4.7 \mathrm{~mm} \mathrm{Hg}$ with 2 and $4 \mu \mathrm{g} / \mathrm{kg} / \mathrm{min}$ dopamine, respectively ( $p$ $<0.05$ versus control). DBP also increased from $17.4 \pm 4 \mathrm{~mm}$ $\mathrm{Hg}$ to $20.2 \pm 5.5$ and $23.3 \pm 2.2 \mathrm{~mm} \mathrm{Hg}$ with 2 and $4 \mu \mathrm{g} / \mathrm{kg} /$ min drug infusion, respectively. However, for the DBP, only the increase with $4 \mu \mathrm{g} / \mathrm{kg} / \mathrm{min}$ reached statistical significance $(p<$ 0.05 versus control). No significant change in heart rate occurred. $\mathrm{U}_{\mathrm{v}}$, measured in this group of preterm infants during the control and the DA-4 periods, increased significantly from $0.027 \pm 0.012$ to $0.059 \pm 0.019 \mathrm{~mL} / \mathrm{min} / \mathrm{kg}(p<0.05)$. In the five children, blood pressure and heart rate did not change, whereas $U_{v}$ increased moderately with $2 \mu \mathrm{g} / \mathrm{kg} / \mathrm{min}$ dopamine.
Figure 3 summarizes the changes in steady state plasma dopamine and norepinephrine levels, and plasma dopamine clearance rates during the study. Control dopamine levels were below the sensitivity of our assay $(<2.61 \mathrm{nmol} / \mathrm{L})$. In the preterm infants, steady state plasma dopamine levels with $2 \mu \mathrm{g} / \mathrm{kg} / \mathrm{min}$ dopamine infusion were significantly higher than those with the same infusion rate in the children. In the preterm neonates, doubling the dose of dopamine resulted in a $60 \%$ increase in steady state plasma dopamine levels. In agreement with earlier reports $(30,31)$, baseline plasma norepinephrine levels were significantly elevated in the preterm infants compared with those in the children. Administration of $2 \mu \mathrm{g} / \mathrm{kg} / \mathrm{min}$ dopamine resulted in significant elevations in plasma norepinephrine levels in both groups. However, $4 \mu \mathrm{g} / \mathrm{kg} / \mathrm{min}$ dopamine did not cause any further increase in plasma norepinephrine in preterm neo-
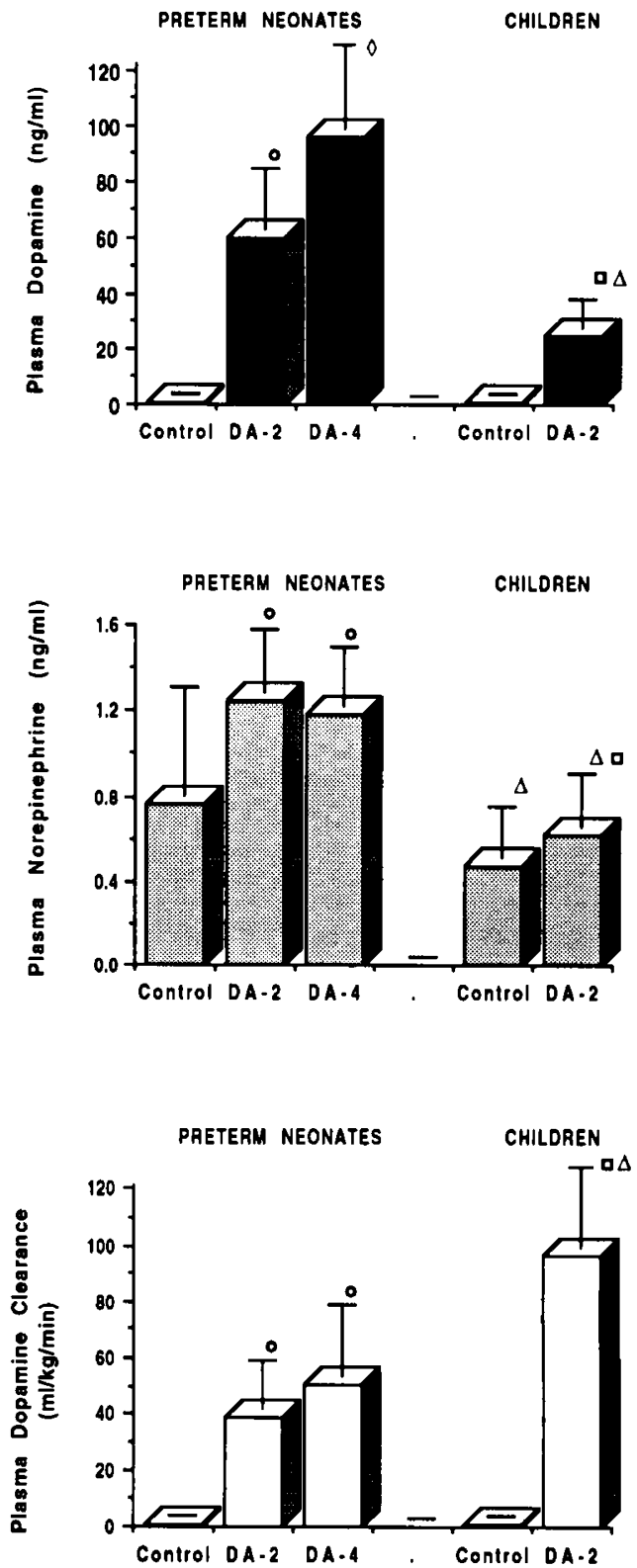

Fig. 3. Steady state plasma dopamine (upper panel) and norepinephrine (middle panel) levels $(\mathrm{nmol} / \mathrm{L}$ ) and plasma dopamine clearance $(\mathrm{L} /$ $\mathrm{min} / \mathrm{kg}$, lower panel) in 14 preterm neonates and five children before (control) and during 2 (DA-2) and 4 (DA-4) $\mu \mathrm{g} / \mathrm{kg} / \mathrm{min}$ dopamine therapy. $0, p<0.05 v s$ control in preterm infants (ANOVA); $\square, p<0.05$ $v s$ control in children (paired $t$ test); $\diamond, p<0.05 v s$ control and DA-2 in preterm infants (ANOVA); $\Delta, p<0.05 v s$ the same period in preterm infants (unpaired $t$ test). 
nates. Plasma dopamine clearance rates with $2 \mu \mathrm{g} / \mathrm{kg} / \mathrm{min}$ dopamine infusion were significantly higher in the children than in the preterm infants. In the preterm infants, plasma dopamine clearance was somewhat higher with $4 \mu \mathrm{g} / \mathrm{kg} / \mathrm{min}$ than with 2 $\mu \mathrm{g} / \mathrm{kg} / \mathrm{min}$ of dopamine.

SBP and plasma dopamine concentrations were significantly correlated $(r=0.731, p<0.05)$. DBP correlated poorly but significantly with plasma dopamine levels $(r=0.329, p<0.05)$ as did SBP with plasma norepinephrine concentrations $(r=0.43$, $p<0.05$ ). Finally, in agreement with recent findings (4), we also found a significant but poor correlation between plasma dopamine and norepinephrine concentrations $(r=0.357, p<0.05)$.

\section{DISCUSSION}

In the present study, we have demonstrated that hypotensive preterm infants during the first days of life exhibit an increased sensitivity to the pressor effects of dopamine. The data also suggest the existence of a fairly mature renal tubular dopaminergic system in the human preterm neonate and underline the importance of the direct tubular actions of the drug. Furthermore, our findings present indirect evidence for changes in the $\mathrm{CBF}$ of preterm infants that parallel the alterations in systemic blood pressure and for the presence of an immature but not completely ineffective CBF autoregulation in the human preterm neonate. The observed decreased metabolism of dopamine in the sick preterm neonate during the first days of life may contribute to the enhanced cardiovascular and renal response to the drug.

Our findings indicate that preterm infants on the first days of life, unlike children and adults $(6,7,10,11)$, respond to low doses of dopamine with an increase in blood pressure and no significant changes in heart rate. This difference in response may be related to developmental changes in the sensitivity of adrenergic receptors to dopamine as well as to the maturation of hepatic and renal clearance mechanisms. In children and adults, dopamine, in increasing concentrations, activates the dopaminergic, then the $\beta$-adrenergic, and finally the $\alpha$-adrenergic receptors (10). The present findings and our earlier observations $(3,8$, $32,33)$ as well as those reported by others $(2,34)$ suggest that the order of receptor sensitivity is different in the preterm infant, i.e. clinical signs of stimulation of the $\alpha$-adrenoreceptors and dopamine receptors occur before those of the $\beta$-adrenoreceptors. Thus, the enhanced responsiveness of the preterm infant to the pressor effects of dopamine during the early postnatal period is mainly due to the increased $\alpha$-adrenergic sensitivity of the immature cardiovascular system (22). However, the recently documented existence of a positive inotropic response (34) may also play a role in this phenomenon. Furthermore, the decreased clearance rate of dopamine found in the present study in sick preterm neonates may also contribute to their enhanced cardiovascular response to the drug during the first few days of life. Finally, the findings that GFR increases out of proportion to the drug-induced rise in blood pressure and that $U_{U N}$ significantly decreases despite the increase in $U_{V}$ suggest that a fairly mature dopaminergic regulation of renal hemodynamics also plays a role in the observed pattern of cardiovascular response to low doses of dopamine in the preterm neonate (at least beyond the 27th wk of gestation). Consistent with the maturational process, term neonates are less sensitive than preterm infants to the pressor effects of low-dose dopamine therapy. However, according to our present findings, at least on the first day of life, they still exhibit a somewhat enhanced pressor response compared with older age groups $(2,35)$.

Our earlier studies provided indirect evidence for the existence of the direct tubular actions of dopamine in the 1-d-old preterm human neonate $(24,32,33)$. The present findings demonstrate that 2 and $4 \mu \mathrm{g} / \mathrm{kg} / \mathrm{min}$ dopamine induce significant but similar increases in $U_{v}$ and sodium excretion in this age group, whereas the higher dose of the drug also results in statistically significant elevations in blood pressure and $\mathrm{C}_{\mathrm{cr}}$. Thus, while maintaining blood pressure and GFR comparable to those in untreated, normotensive controls, $2 \mu \mathrm{g} / \mathrm{kg} / \mathrm{min}$ dopamine induces maximum diuresis and natriuresis in the 1-d-old mildly hypotensive preterm neonate. Therefore, these findings support our previous observations $(24,32,33)$ and demonstrate that the dopamineinduced diuresis and natriuresis also result from the direct tubular effects of the drug.

When explaining the mechanisms of the diuretic and natriuretic actions of dopamine, earlier reports emphasized the importance of the drug-induced cardiovascular and renal hemodynamic changes $(10,11,20)$. The importance of the direct tubular actions of dopamine in producing diuresis and natriuresis has only recently been recognized $(9,14)$. In the kidney, endogenous and exogenous dopamine inhibit $\mathrm{Na}^{+}, \mathrm{K}^{+}$-ATPase $(9,12,13)$ and $\mathrm{Na}^{+} / \mathrm{H}^{+}$exchanger (15) activity along the nephron and in the proximal tubule, respectively. Furthermore, in the distal tubule, dopamine attenuates the actions of antidiuretic hormone and aldosterone $(14,16)$. All these tubular actions of dopamine result in decreased sodium and water reabsorption along the nephron and thus lead to significant natriuresis and diuresis $(9,14)$. Because our findings demonstrate the presence of the direct tubular effects of dopamine in the preterm neonate, they also imply that functionally mature renal tubular dopamine receptors and postreceptor responses are present in the human preterm infant at least beyond the $27 \mathrm{th}$ wk of gestation.

Our findings also provide indirect evidence for the presence of renal hemodynamic actions of dopamine in the 1 -d-old preterm neonate. The increase in $\mathrm{C}_{\mathrm{cr}}$ with $4 \mu \mathrm{g} / \mathrm{kg} / \mathrm{min}$ dopamine indicates a blood pressure elevation-induced rise in GFR without concomitant renal vasoconstriction. Furthermore, the decrease in $U_{U N}$ suggests a dopamine-induced selective enhancement of the medullary circulation ["urea wash-out phenomenon" (24)]. These renal hemodynamic effects of dopamine indicate the presence of functionally mature vascular dopamine receptors and postreceptor responses in the kidney of the 1-d-old preterm infant.

The dopamine-induced decrease in free water clearance is most likely the consequence of the increased solute excretion. Although urinary potassium excretion tended to increase, it did not significantly change with either dose of dopamine. Because the excretion of potassium is influenced by many factors mainly of distal tubular origin and independent of the renal dopaminergic system (36), the immaturity of distal tubular function of the preterm human infant (36) could explain the observed pattern of potassium excretion. The significant increase in phosphate excretion with dopamine treatment results from the direct proximal tubular effects of the drug $(36,37)$. Furthermore, because the major constituent of titratable acid in the urine is $\mathrm{H}_{2} \mathrm{PO}_{4}^{-}$, the significant increase in $\mathrm{U}_{\mathrm{TA}}$ is most likely the consequence of decreased phosphate reabsorption rather than increased acid production. This assumption is supported by the fact that $U_{\mathrm{NH} 4}$ remained unchanged.

In the present study, we also examined whether 2 and $4 \mu \mathrm{g} /$ $\mathrm{kg} / \mathrm{min}$ dopamine, or the drug-induced elevation in blood pressure, would affect CBF in hypotensive term and preterm neonates. Our study design allowed us to evaluate temporal changes in $\mathrm{CBF}$ while patients received the same dose of dopamine without further significant changes in their blood pressure.

Pulsed Doppler ultrasound measurements of CBF velocity are considered reliable indicators of $\mathrm{CBF}$ provided no significant changes in heart rate and hematocrit occur and the angle of insonation of the ACA is constant during measurements $(18,19$, 21,28 ). All these criteria were met in our study. Although the technique has its limitations when used as a measure for estimation of the absolute volume of CBF (27), its use for comparison of serial measurements of $\mathrm{CBF}$ velocity provides valuable and reproducible information. We also calculated the PI and used it as a measure of change in CBF velocity $(27,28)$. Changes in the PI are inversely and significantly related to changes in 
CBF in human preterm and term neonates (28). Use of PI for serial comparisons of CBF velocity is a simple, descriptive, and valuable way to characterize changes in $\operatorname{CBF}(27,28)$ provided that the alterations in ESFV and EDFV account for changes in PI (27), as was the case in our study.

Within the observed blood pressure range and at least $15 \mathrm{~min}$ after the initiation of dopamine infusion, we found an intact autoregulation of CBF in the moderately hypotensive term infants. However, as indicated by the decrease in PI and increase in ESFV and EDFV in the hypotensive preterm neonates, the dopamine-induced increase in blood pressure was associated with a temporary elevation in CBF. Effective autoregulation of CBF in preterm neonates occurred only 50 to $90 \mathrm{~min}$ after the start of the dopamine infusion.

If dopamine had a direct, selective vasodilatory effect on the cerebral vasculature, one would expect to see sustained increases in CBF occur independently of changes in systemic blood pressure. The lack of a sustained increase in CBF suggests the absence of a significant selective vasodilatory effect of dopamine on the cerebral vasculature in the human preterm infant. Furthermore, no alterations in heart rate, blood gases, and Hct that could have influenced CBF independently of the dopamine-induced blood pressure changes occurred during the study.

Although in our hypotensive patients the PI during the control period was in the predicted "normal" range for both preterm and term infants $(27,28)$, it is not known whether their absolute CBF was indeed normal. Our findings only demonstrate the alterations in CBF, and they indicate that even small changes in systemic blood pressure may temporarily and adversely influence cerebral perfusion in sick preterm infants.

Finally, we measured plasma dopamine and norepinephrine levels and calculated plasma dopamine clearance rates in 1- to 4-d-old preterm infants and compared the findings with those obtained in 5- to 15-y-old children with normal liver and kidney functions receiving $2 \mu \mathrm{g} / \mathrm{kg} / \mathrm{min}$ dopamine infusions. Several other studies have recently been published on the dopamineinduced changes in plasma catecholamine levels in infants, children, and adults $(4,34,38-40)$. However, data on preterm infants are scanty and, in most of the studies, findings in preterm infants are grouped together with those in term neonates $(4,34,40)$. The studies agree that there is a significant variability among patients in plasma dopamine levels during dopamine infusion $(4,34,39,40)$. It is also accepted that steady state plasma dopamine levels are uniformly increased in the presence of liver and/or kidney failure (39). Because $\sim 20 \%$ of the infused dopamine is converted to norepinephrine, and dopamine also triggers the release of stored norepinephrine, a linear relationship between plasma dopamine and norepinephrine exists in adults and children $(4,38)$. However, sick preterm infants with significantly increased sympathetic activity may not exhibit a dose-dependent increase in plasma norepinephrine during dopamine infusion (34).

We found that, in children, steady state plasma dopamine levels and plasma dopamine clearance rates were within the reported range for adults (38). Furthermore, although baseline plasma norepinephrine levels were at the upper end of the normal range, plasma norepinephrine levels increased as expected with dopamine administration.

Consistent with earlier reports $(30,31)$, baseline plasma norepinephrine levels in the preterm infants were higher than those in the children. Steady state plasma norepinephrine levels rose during $2 \mu \mathrm{g} / \mathrm{kg} / \mathrm{min}$ dopamine administration but not with $4 \mu \mathrm{g} /$ $\mathrm{kg} / \mathrm{min}$ drug infusion. The lack of a further rise in plasma norepinephrine concentration with the higher dose may be explained by the significantly elevated baseline sympathetic activity in these infants $(4,30,34)$. We found significantly lower plasma dopamine clearance rates with $2 \mu \mathrm{g} / \mathrm{kg} / \mathrm{min}$ dopamine in the preterm neonates than in the children. In the preterm infants, the steady state plasma dopamine levels were comparable to those obtained with the same doses in sick infants and children with liver and/or renal dysfunction (39). It has also been suggested that sick preterm neonates may have decreased plasma dopamine clearance rates during the first days of life (40). Therefore, the elevated steady state plasma dopamine concentration in our sick preterm neonates is most likely the consequence of their impaired metabolic function due to their early postnatal age and severe underlying disease.

In the present study, we have found that hypotensive preterm infants during the first days of life exhibit an increased sensitivity to the pressor effects of dopamine. Based on our findings, we suggest that rapid i.v. infusions of colloid and/or crystalloid in the hypotensive and/or oliguric sick preterm infant should be avoided and propose that dopamine infusion should be started early and at low doses $(2 \mu \mathrm{g} / \mathrm{kg} / \mathrm{min})$. The dose of the drug should be increased slowly and adjusted according to the cardiovascular and renal response of the patient. The observations that sudden and significant changes in systemic blood pressure, and thus in CBF, may contribute to the development of IVH during the first days of life (18) lend further support to these suggestions. However, treatment of systemic hypotension using this approach should not be delayed, because decreased tissue perfusion of the brain will have devastating long-term consequences (17).

Acknowledgment. The authors thank Dr. Ann R. Stark for her valuable comments during the preparation of the manuscript.

\section{REFERENCES}

1. Zaritsky A, Chernow B 1984 Use of catecholamines in pediatrics. J Pediatr 105:341-350

2. DiSessa TG, Leitner M, Ti CC, Gluck L, Coen R, Friedman WF 1981 The cardiovascular effects of dopamine in the severely asphyxiated neonate. $J$ Pediatr 99:772-776

3. Seri I, Tulassay T, Kiszel J, Machay T, Csömör S 1984 Cardiovascular response to dopamine in hypotensive preterm neonates with severe hyaline membrane disease. Eur J Pediatr 142:3-9

4. Stopfkuchen H, Racke K, Schwörer H, Queisser-Luft A, Vogel K 1991 Effects of dopamine infusion on plasma catecholamines in preterm and term newborn infants. Eur J Pediatr 150:503-506

5. Cuevas L, Yeh TF, John EG, Cuevas D, Plides RS 1991 The effect of low-dose dopamine infusion on cardiopulmonary and renal status in premature newborns with respiratory distress syndrome. Am J Dis Child 145:799-803

6. Driscoll DJ, Gillette PC, McNamara DG 1978 The use of dopamine in children. J Pediatr 92:309-314

7. Lang P, Williams RG, Norwood WI, Castaneda AR 1980 The hemodynamic effects of dopamine in infants after corrective cardiac surgery. J Pediatr 96:630-634

8. Rudas G, Bors ZS, Schuler D, Seri I 1989 Effect of dopamine (DA)-induced blood pressure (BP) elevation on cerebral blood flow (CBF) in the sick preterm (PTN) and term (TN) neonate. Pediatr Res 25:229A (abstr)

9. Seri I 1990 Dopamine and natriuresis: mechanism of action and developmental aspects. Am J Hypertens 3:82S-86S

10. Goldberg LI 1972 Cardiovascular and renal actions of dopamine: potential clinical applications. Pharmacol Rev 24:1-29

11. Lee MR 1982 Dopamine and the kidney. Clin Sci 62:439-448

12. Aperia A, Bertorello A, Seri I 1987 Dopamine causes inhibition of $\mathrm{Na}^{+}, \mathrm{K}^{+}-$ ATPase activity in rat proximal convoluted tubule segments. Am J Physiol 252:F39-F45

13. Seri I, Kone BC, Gullans SR, Aperia A, Brenner BM, Ballermann BJ 1988 Locally formed dopamine inhibits $\mathrm{Na}^{+}, \mathrm{K}^{+}$-ATPase activity in rat renal cortical tubule cells. Am J Physiol 255:F666-F673

14. Felder RA, Felder CC, Eisner PA, Jose P 1989 The dopamine receptor in the adult and maturing kidney. Am J Physiol 257:F315-F327

15. Felder CC, Campbell T, Albrecht F, Jose PA 1990 Dopamine inhibits $\mathrm{Na}^{+} / \mathrm{H}^{+}$ exchanger activity in renal BBMV by stimulation of adenylate cyclase. Am J Physiol 259:F297-F303

16. Huo TL, Healy DP 1991 Prostaglandin $E_{2}$ production in rat IMCD cells. II. Possible role for locally formed dopamine. Am J Physiol 261:F655-F662

17. Calvert SA, Hoskins EM, Fong KW, Forsyth SC 1986 Periventricular leukomalacia: ultrasonic diagnosis and neurological outcome. Acta Paediatr Scand 75:489-496

18. Van Bel F, Van de Bor M, Stijnen T 1987 Aetiological role of cerebral blood flow alterations in development and extension of peri-intraventricular haemorrhage. Dev Med Child Neurol 29:601-614

19. Calvert SA, Ohlsson A, Hosking MC, Erksine L, Fong KW, Shennan AT 1988 Serial measurements of cerebral blood flow velocity in preterm infants during the first 72 hours of life. Acta Paediatr Scand 77:625-631

20. Jorch G, Jorch N 1987 Failure of autoregulation of cerebral blood flow in neonates studied by the pulsed Doppler ultrasound of the internal carotid artery. Eur J Pediatr 146:468-472 
21. Van de Bor M, Walther FJ 1991 Cerebral blood flow velocity regulation in preterm infants. Biol Neonate 59:329-335

22. Feider RA, Pelayo JC, Calcagno PL, Eisner GM, Jose PA 1983 Alpha adrenoreceptors in the developing kidney. Pediatr Res 17:177-180

23. Seikaly MG, Arant BS 1992 Development of renal hemodynamics: glomerular filtration and renal blood flow. Clin Perinatol 19:1-14

24. Tulassay T, Seri I, Machay T, Kiszel J, Varga J, Csömör S 1983 Effects of dopamine on renal functions in premature infants with respiratory distress syndrome. Int J Pediatr Nephrol 4:19-23

25. Bada HS, Korones SB, Perry EH, Arheart KL, Ray JD, Pourcyrous M, Magill HL, Runyan W, Somes GW, Clark FC, Tullis KV 1990 Mean arterial blood pressure changes in premature infants and those at risk for intraventricular hemorrhage. J Pediatr 117:607-614

26. Emery EF, Greenough A 1992 Non-invasive blood pressure monitoring in preterm infants receiving intensive care. Eur J Pediatr 151:136-139

27. Volpe JJ, Perlman JM, Hill A, McMenamin JB 1982 Cerebral blood flow velocity in the human newborn: the value of its determination. Pediatrics $70: 147-152$

28. Greisen G, Johansen K, Ellison PH, Fredriksen PS, Mali J, Friis-Hansen B 1984 Cerebral blood flow in the newborn infant: comparison of Doppler ultrasound and ${ }^{133}$ xenon clearance. J Pediatr 104:411-418

29. Peuler JD, Johnson GA 1977 Simultaneous single isotope radioenzymatic assay of plasma norepinephrine, epinephrine and dopamine. Life Sci 21:625636

30. Gabriel M, Hunnerman DH, Gahr M 1984 Plasma levels of catecholamine metabolites in the newborn period. Biol Neonate 44:203-209
31. Ross RD, Daniels SR, Schwartz DC, Hannon DW, Shukla R, Kaplan S 1987 Plasma norepinephrine levels in infants and children with congestive heart disease. Am J Cardiol 59:911-914

32. Seri I, Tulassay T, Kiszel J, Csömör S 1984 The use of dopamine for the prevention of the renal side effects of indomethacin in premature infants with patent ductus arteriosus. Int J Pediatr Nephrol 5:209-214

33. Seri I, Hajdu J, Kiszel J, Tulassay T, Aperia A 1988 Effect of low-dose dopamine infusion on urinary prostaglandin $E_{2}$ excretion in sick, preterm infants. Eur J Pediatr 147:616-620

34. Padbury JF, Agata Y, Baylen BG, Ludlow JK, Polk DH, Goldblatt E, Pescetti J 1986 Dopamine pharmacokinetics in critically ill newborn infants. J Pediatr 110:293-298

35. Walther FJ, Siassi B, Ramadan NA, Wu PYK 1985 Cardiac output in newborn infants with transient myocardial dysfunction. J Pediatr 107:781-785

36. Jones DP, Chesney RW 1992 Development of tubular function. Clin Perinatol 19:33-57

37. Ortola FV, Seri I, Downes S, Brenner BM, Barllermann BJ 1990 Dopamine $_{1}$ receptor blockade inhibits ANP-induced phosphaturia and calciuria in rats. Am J Physiol 259:F138-F146

38. Järnberg PO, Bengsston L, Ekstrand J, Hamberger B 1981 Dopamine infusion in man. Plasma catecholamine levels and pharmacokinetics. Acta Anaesth Scand 25:328-331

39. Zaritsky A, Lotze A, Stull R, Goldstein DS 1988 Steady-state dopamine clearance in critically ill infants and children. Crit Care Med 16:217-220

40. Bhatt-Mehta V, Nahata MC, McClead RE, Menke JA 1991 Dopamine pharmacokinetics in critically ill newborn infants. Eur J Clin Pharmacol 40:593597 